\title{
PENGARUH TEKNIK ROOLING MASSAGE TERHADAP KELANCARAN PENGELUARAN ASI PADA IBU HAMIL TRIMESTER III
}

\author{
Wiwi Wardani Tanjung ${ }^{l}$, Eva Yusnita Nasution ${ }^{2}$, \\ Akademi Kebidanan Darmais Padangsidimpuan ${ }^{1,2}$ \\ e-mail: ${ }^{1}$ wiwiwardani85@gmail.com
}

\begin{abstract}
The Exclusive Breastfeeding has been shown to have an impact better on health growth, development, and all the impacts short and long term, but there are still many mothers who do not provide exclusive breastfeeding. One of the reasons mom does not provide exclusive breastfeeding to the baby was due to the release of breast milk that was not smooth that happened due to inhibition of the hormone prolactin which produces breast milk. Rolling Massase Technique was one action which gives a relaxing sensation to the mother and smooth the flow of nerves as well as the milk duct. The purpose of this research was to know the influence of rooling massage techniques on the smooth release of breast milk in third trimester pregnant women in the work area In Public Health Center Of Batunadua 2020. This type of research was quantitative research with a quasi experimental design used the Post Test Only Design with Control Group design. The population in this study are all trimester III pregnant women who came to the Public Health Center Of Batunadua as many as 32 people. The sample in this study was 16 people in the intervention group and 16 people in the control group by used accidental sampling method. The analysis used was the Wilcoxon test. The results showed that massage rooling technique effect on smoothness expressing breastmilk in pregnant women Trimester III with $p$ value $=0.008(p<0.05)$. It was hoped that the Public Health Center Of Batunadua In Padangsdimpuan to do health education or health promotion which can be given to pregnant women to prepare for smooth operation expressing breastmilk like perform rooling massage techniques.
\end{abstract}

Keywords: rolling massage, release of breastfeeding, pregnant women trimester III

\begin{abstract}
ABSTRAK
Pemberian ASI Eksklusif telah terbukti memberikan dampak yang lebih baik terhadap pertumbuhan kesehatan, perkembangan, dan semua dampak jangka pendek maupun panjang, namun masih banyak ibu yang tidak memberikan ASI Eksklusif. Salah satu alasan ibu tidak memberikan ASI Eksklusif kepada bayinya adalah karena pengeluaran ASI yang tidak lancar yang terjadi akibat terhambatnya hormon prolaktin yang memproduksi ASI. Tehnik Rolling Massase merupakah salah satu tindakan yang memberikan sensasi relaks pada ibu dan melancarkan aliran syaraf serta saluran ASI. Tujuan Penelitian ini adalah untuk mengetahui pengaruh pengaruh teknik rooling massage terhadap kelancaran pengeluaran ASI pada ibu hamil trimester III di wilayah kerja Puskesmas Batunadua Tahun 2020. Jenis penelitian adalah penelitian kuantitatif dengan desain quasi eksperimen menggunakan rancangan Post Test Only Design with Control Group. Populasi dalam penelitian ini adalah seluruh ibu hamil Trimester III yang datang ke Puskesmas Batunadua sebanyak 32 orang. Sampel dalam penelitian ini adalah adalah 16 orang pada kelompok intervensi dan 16 orang pada kelompok kontrol dengan menggunakan metode accidental sampling. Analisa yang digunakan adalah uji Wilcoxon. Hasil penelitian menunjukkan bahwa teknik rooling massage berpengaruh terhadap kelancaran pengeluaran ASI pada ibu hamil Trimester III dengan nilai $p=0,008(p<0,05)$. Diharapkan kepada Puskesmas Batunadua Kota Padangsdimpuan untuk melakukan pendidikan kesehatan ataupun promosi kesehatan yang dapat diberikan kepada ibu hamil untuk mempersiapkan kelancaran pengeluaran ASI seperti melakukan teknik rooling massage
\end{abstract}

Kata Kunci : rooling massage, pengeluaran asi, ibu hamil trimester III

\section{PENDAHULUAN}

\section{Latar Belakang (Opsional)}

Pengeluaran Air Susu Ibu (ASI) merupakan suatu interaksi yang sangat kompleks antara rangsangan mekanik, saraf dan bermacam-macam hormon. Pengaturan hormon terhadap pengeluaran
ASI dapat dibedakan menjadi 3 yaitu pembentukan kelenjar payudara, pembentukan ASI dan pemeliharaan pengeluaran ASI. Masalah yang sering 
dikeluhkan oleh ibu menyusui adalah produksi ASI yang kurang, $(1,2)$

Menurut Nutrition dan Health Surveillance System (NHSS) kerjasama dengan Balitbangkes dan Helen Keller Internasional tahun 2010, menunjukkan cakupan nutrisi ibu menyusui yang terpenuhi di perkotaan antara 4\% sampai $12 \%$ sedangkan di pedesaan $4 \%$ sampai $25 \%$. Sebagai gambaran data pemberian ASI berdasarkan Suervey Demografi Kesehatan Indonesia (SDKI) tahun 2007, Angka Cakupan ASI Eksklusif 6 bulan di Indonesia hanya $32,3 \%$, masih jauh dari rata - rata dunia, yaitu $38 \%$. Sementara itu saat ini jumlah bayi dibawah 6 bulan yang di beri susu formula meningkat dari $16,7 \%$ pada tahun 2007 menjadi 27,9\% pada tahun 2012. (3)

Berdasarkan data dari profil Kesehatan Provinsi Sumatera Utara (2017), cakupan persentasi bayi yang diberi ASI eksklusif sebesar 56,6\%. Hal ini masih jauh dari target nasional sebesar $80 \%$. Berdasarkan data dari profil Dinas Kesehatan Kota Padangsidimpuan tahun 2017, cakupan ASI Eksklusif masih rendah yaitu sebesar 25,4\%. Target cakupan ASI Eksklusif di Kota Padangsidimpuan sebesar $80 \%$.. (4)

Salah satu alasan ibu tidak memberikan ASI Eksklusif kepada bayinya adalah karena pengeluaran ASI yang tidak lancar yang terjadi akibat terhambatnya hormon prolaktin yang memproduksi ASI, juga karena dihambat oleh kadar esterogen yang begitu tinggi setelah melahirkan, sehingga ASI belum bisa keluar atau hanya keluar sedikit (5).

Perawatan payudara selama kehamilan merupakan salah satu hal yang penting yang harus diperhatikan pada saat kehamilan sebagai persiapan menyusui nantinya. Perawatan payudara dengan merangsang buah dada akan memengaruhi hypopise untuk mengeluarkan hormon progesteron, esterogen dan hormon oxytocin lebih banyak lagi. Salah satu perawatan payudara yang dapat dilakukan pada ibu hamil dan ibu menyusui adalah Rolling Massage. Rolling massage yaitu pemijatan pada tulang belakang (costae 5-6 sampai scapula dengan gerakan memutar) yang biasanya dilakukan pada ibu ibu setelah melahirkan yang dapat membantu kerja hormon oksitosin dalam pengeluaran ASI. Tehnik Rolling Massase (Punggung) adalah tindakan yang memberikan sensasi relaks pada ibu dan melancarkan aliran syaraf serta saluran ASI kedua payudara (6).

Hasil penelitian Surrinah (2010) tentang keberhasilan ibu menyusui, terdapat faktor penting tentang perawatan payudara, hal ini terbukti dengan diperolehnya data dari 115 ibu postpartum yang terbagi dalam dua kelompok, dimana angka keberhasilan menyusui pada $50 \mathrm{ibu}$ yang tidak melakukan perawatan payudara adalah $26,8 \%$ Ini sangat rendah jika dibandingkan dengan 98,1\% keberhasilan menyusui dari kelompok ibu yang melakukan perawatan payudara yang berjumlah 65 orang. (7)
Hasil penelitian yang dilakukan oleh Windi (2017) yang menemukan bahwa kelancaran pengeluaran ASI sesudah diberikan intervensi, didapatkan nilai $p<0,000$ artinya Terdapat pengaruh perawatan payudara dengan teknik massage rolling pada ibu hamil trimester III terhadap kelancaran pengeluaran ASI postpartum di wilayah kerja Puskesmas Perumnas II Pontianak Barat. Kelancaran pengeluaran ASI pada kelompok intervensi $(87,5 \%)$ sedangkan pada kelompok kontrol $(31,3 \%)$. (8)

Studi pendahuluan yang telah dilakukan ditemukan jumlah ibu hamil trimester III (36-40 minggu) yang berada di wilayah kerja Puskesmas Batunadua pada bulan April 2020 adalah sebanyak 31 orang, bulan Mei 2020 sebanyak 26 orang dan pada bulan Juni 2020 sebanyak 34 orang. Survey dilakukan peneliti di wilayah kerja Puskesmas Batunadua bahwa hanya $41,3 \%$ bayi mendapatkan ASI Eksklusif. Wawancara yang peneliti lakukan kepada 4 ibu menyusui mengatakan bahwa ASI tidak dapat keluar ataupun tidak lancar sehingga menyebabkan bayi mengkonsumsi susu formula dan bahwa belum pernah dilakukan perawatan payudara dengan teknik rooling massage selama kehamilannya. Berdasarkan hal tersebut, maka peneliti tertarik untuk melakukan penelitian tentang Pengaruh Teknik Rooling Massage terhadap Kelancaran Pengeluaran ASI pada Ibu Hamil Trimester III.

\section{Tujuan Penelitian (Opsional)}

Untuk mengetahui pengaruh teknik rooling massage terhadap kelancaran pengeluaran ASI pada ibu hamil trimester III.

\section{Hipotesis (Opsional)}

Ada pengaruh pengaruh teknik rooling massage terhadap kelancaran pengeluaran ASI pada ibu hamil trimester III.

\section{METODE}

Jenis penelitian ini adalah penelitian kuantitatif dengan menggunakan rancangan desain quasy eksperimen Post Test Only Design with Control Group. Penelitian ini wilayah Kerja Puskesmas Batunadua Kota Padangsidimpuan dari bulan Maret - Agustus 2020.

Populasi dalam penelitian ini adalah seluruh ibu hamil Trimester III yang datang ke Puskesmas Batunadua sebanyak 32 orang. Sampel penelitian adalah sebagian yang diambil dari keseluruhan subjek yang diteliti dan dianggap mewakili populasi ini. Teknik pengambilan sampel dalam penelitian ini menggunakan tehnik accidental sampling. Besar sampel dalam penelitian ini adalah 16 orang pada kelompok intervensi dan 16 orang pada kelompok kontrol. 
Prosedur penelitian dimulai dari pengumpulan data yaitu pertama peneliti mengajukan izin penelitian kepada Kepala Puskesmas Batunadua, kemudian meminta izin untuk melakukan penelitian kepada responden dan menjelaskan tujuan diadakannya penelitian ini serta meminta persetujuan responden. Responden kelompok perlakuan diberikan intervensi rooling massage yang dilakukan dua kali sehari setiap pagi dan sore selama 5 menit dan untuk responden kelompok kontrol diberitahukan dan di kontrol untuk tidak melakukan rooling massage. Setelah perawatan payudara dilakukan selama 3 hari pada kehamilan trimester III, maka peneliti menunggu responden melahirkan untuk melihat pengeluaran ASI yang dikeluarkan ibu setelah melahirkan. Setelah itu pengukuran dilakukan dengan lembar kuesioner yang diberikan kepada ibu postpartum yang diisi untuk mendapatkan data dari hasil pengeluaran ASI. Setelah data terkumpul, maka peneliti melakukan pengolahan data.

\section{HASIL}

Hasil penelitian dapat dilihat pada tabel berikut:

Tabel 1

Kelancaran Pengeluaran ASI Responden Kelompok Intervensi dan Kelompok Kontrol di Wilayah Kerja Puskesmas Batunadua Kota Padangsidimpuan

\begin{tabular}{|l|c|c|c|c|}
\hline \multirow{2}{*}{$\begin{array}{l}\text { Kelancaran } \\
\text { Pengeluaran } \\
\text { ASI }\end{array}$} & \multicolumn{2}{|c|}{ Kel. Intervensi } & \multicolumn{2}{c|}{ Kel. Kontrol } \\
\cline { 2 - 5 } & $\mathrm{F}$ & $\%$ & $\mathrm{~F}$ & $\%$ \\
\hline Lancar & 13 & 81,2 & 6 & 37,5 \\
\hline Tidak Lancar & 3 & 18,8 & 10 & 62,5 \\
\hline Jumlah & 16 & 100,0 & 16 & 100,0 \\
\hline
\end{tabular}

Berdasarkan Tabel 1 didapatkan hasil penelitian pada kelompok intervensi mayoritas pengeluaran ASI lancar yaitu 13 responden $(81,2 \%)$ Pada kelompok kontrol mayoritas pengeluaran ASI tidak lancar yaitu 10 responden $(62,5 \%)$.

Tabel 2

Pengaruh Teknik Rooling Massage Terhadap Kelancaran Pengeluaran ASI pada Ibu Hamil Trimester III di Wilayah Kerja Puskesmas Batunadua Kota Padangsidimpuan

\begin{tabular}{|l|l|c|c|c|c|}
\hline No & $\begin{array}{l}\text { Kelancaran } \\
\text { Pengeluaran } \\
\text { ASI }\end{array}$ & $\mathbf{n}$ & Mean & SD & Signifikan \\
\hline 1 & $\begin{array}{l}\text { Post Test } \\
\text { Kelompok } \\
\text { Intervensi }\end{array}$ & 16 & 1.19 & 0.403 & \multirow{2}{*}{0,008} \\
\hline 2 & $\begin{array}{l}\text { Post Test } \\
\text { Kelompok } \\
\text { Kontrol }\end{array}$ & 16 & 1.62 & 0.500 & \\
\hline
\end{tabular}

Berdasarkan Tabel 2 menunjukkan bahwa nilai $p=$ $0,008(p<0,05)$, artinya ada pengaruh teknik rooling massage terhadap kelancaran pengeluaran ASI pada ibu hamil Trimester III di wilayah kerja Puskesmas Batunadua Kota Padangsidimpuan.

\section{PEMBAHASAN}

Berdasarkan hasil penelitian menunjukkan bahwa teknik rooling massage berpengaruh terhadap kelancaran pengeluaran ASI pada ibu hamil Trimester III. Pada penelitian ini ditemukan hasil penelitian pada kelompok intervensi mayoritas pengeluaran ASI lancar dan minoritas pengeluaran ASI tidak lancar, sedangkan pada kelompok kontrol yang tidak dilakukan intervensi mayoritas pengeluaran ASI tidak lancar dan minoritas pengeluaran ASI lancar

Rolling massage merupakan salah satu cara baru dalam menstimulasi pengeluaran ASI. Dengan membuat ibu lebih nyaman diharapkan diharapkan reflek oksitosin dapat meningkat. pemijatan yang dilakukan secara rutin juga memengaruhi kelancaran ASI, semakin sering ibu melakukan pemijatan, semakin meningkat hormon oksitosin sehingga produksi ASI bertambah lancar (1).

Rolling Massage yang di lakukan di ruas tulang belakang ibu akan merasa rileks dan nyaman. Perasaan rileks dan ibu merasa nyaman akan merangsang neurotransmitter kemudian akan merangsang medulla oblongata langsung mengirim pesan ke hipotalamus di hipofise posterior untuk mengeluarkan oksitosin. Oksitosin akan memeras air susu yang telah di produksi keluar dari alveoli atau masuk ke sistem duktus dan selanjutnya mengalir melalui duktus laktiferus masuk ke mulut bayi (1).

Hasil penelitian ini sejalan dengan penelitian yang dilakukan oleh Windi (2017) yang menemukan bahwa kelancaran pengeluaran ASI sesudah diberikan intervensi, didapatkan nilai $p<0,000$ artinya Terdapat pengaruh perawatan payudara dengan teknik massage rolling pada ibu hamil trimester III terhadap kelancaran pengeluaran ASI postpartum di wilayah kerja Puskesmas Perumnas II Pontianak Barat. Kelancaran pengeluaran ASI pada kelompok intervensi $(87,5 \%)$ sedangkan pada kelompok kontrol $(31,3 \%)$. (9)

Penelitian lain yang dilakukan Mawwadah (2015) menyatakan bahwa oksitosin dikeluarkan ketika ibu merasa nyaman, mendapatkan cukup sentuhan, cukup temperatur dan tidak stresss atau ibu dalam kondisi rileks. Pemijatan punggung ibu bertujuan untuk memberi rangsangan kepada kelenjar air susu ibu agar dapat memproduksi susu dan memicu hormone oksitosin atau reflek let down serta memberikan kenyamanan dan menciptakan rasa rileks pada ibu melalui hormone endorphin yang disekresi karena rasa nyaman dan rileks tersebut yang dialami ibu selama pemijatan. Penelitian Desmawati (2013) menunjukkan bahwa ada perbedaan yang bermakna antara waktu pengeluaran ASI ibu postpartum antara kelompok yang diberikan intervensi areola massage dan massage rolling dengan kelompok yang tidak diberikan intervensi. $(10,11)$ 
Berdasarkan hasil penelitian ini menunjukkan bahwa intervensi teknik massage rolling memiliki efek terhadap kelancaran pengeluaran ASI. Hal ini dikarenakan massage rolling dapat menstimulus otototot payudara yang akan mempengaruhi hypofise untuk mengeluarkan hormon progesteron, estrogen, dan oksitosin untuk mengeluarkan ASI terutama apabila dilakukan secara rutin selama kehamilan hingga persalinan. Setelah responden diberikan massage punggung responden merasa rileks dan nyaman. Pengurangan ketidak nyamanan, kelelahan, stress, dan depresi pada ibu akan membantu lancarnya pengeluaran ASI.

Pada penelitian ini teknik rooling massage dilakukan 2 kali dalam sehari selama lima hari yaitu melakukan pemijatan dengan ibu jari maupun punggung telunjuk jari, dengan gerakan memutar perlahan-lahan lurus kebawah sampai di area punggung costae 5-6 (batas garis bra) selama 5 menit. Dari hasil penelitian hal tersebut dapat meningkatkan pengeluaran ASI sehingga kebutuhan bayi akan ASI dapat tercukupi dengan baik. dan bayi tanpak tenang serta tidak rewel.

Hasil penelitian ini menunjukkan terdapat perbedaan nilai rata- rata kelancaran pengeluaran ASI antara ibu hamil pada kelompok dengan ibu hamil pada kelompok intervensi. Pada kelompom intervensi ibu mengatakan lebih sering menyusui bayi 8-10 kali dalam sehari, selain itu sebanyak 8 orang responden ibu mengatakan selalu menyusui selama 5 menit setiap kali menyusui.

Pada penelitian ini terdapat 3 responden yang produksi ASI nya tidak lancar setelah dilakukannya intervensi rooling massage. Hal ini dikarenakan pada 3 responden tersebut puting susu tidak menonjol sehingga ASI tidak dapat keluar. Walaupun sudah dilakukan perawatan payudara agar puting susu menonjol namun hingga persalinan bayi tidak dapat menyusui

\section{KESIMPULAN}

Berdasarkan hasil penelitian didapatkan bahwa ada pengaruh teknik rooling massage terhadap kelancaran pengeluaran ASI pada ibu hamil Trimester III . Hasil penelitian ini dapat menambah wawasan dan pengetahuan responden serta dalam mengaplikasikan teknik rooling massage dan bagi Puskesmas Batunadua Kota Padangsdimpuan diharapkan melakukan pendidikan kesehatan ataupun promosi kesehatan yang dapat diberikan kepada ibu hamil untuk mempersiapkan kelancaran pengeluaran ASI seperti melakukan teknik rooling massage

\section{DAFTAR PUSTAKA}

1. Rini, Susilo dan Kumala, Feti. Panduan Asuhan Nifas dan Evidence Based Practice. Yogyakarta: Deepublish; 2018.

2. Roesli, Utami, Mengenal ASI Eksklusif . Jakarta: PT Pustaka Pembangunan Swadaya Nusantara; 2013.

3. Krisnatuti. D., Yenrina, R. Makanan Pendamping ASI. Jakarta: Puspa Swara; 2011.

4. Dinkes Provinsi Sumatera Utara, Profil Kesehatan Provinsi Sumatera Utara;2017.

5. Fitriyani. Strategi Kesiapan Pemberian Asi Eksklusif Melalui Breast Care Pada Ibu Primigravida. Jurnal Fakultas Kesehatan masyarakat, ISSN: 2355-0643.; 2018.

6. Perinasia. Program Manajemen Laktasi. Jakarta: Bina Rupa Aksara; 2010.

7. Suririnah. Buku Pintar Mengasuh Batita. PT. Gramedia Pustaka Utama. Jakarta; 2010.

8. Windi Audia Sari, Pengaruh Perawatan Payudara dengan Teknik massage Rooling pada Ibu Hamil Trimester III terhadap Kelancaran Pengeluaran ASI Postpartum. Pontianak: Fakultas Kedokteran Universitas Tanjungpura; 2017.

9. Windi Audia Sari, Pengaruh Perawatan Payudara dengan Teknik massage Rooling pada Ibu Hamil Trimester III terhadap Kelancaran Pengeluaran ASI Postpartum. Pontianak: Fakultas Kedokteran Universitas Tanjungpura; 2017.

10. Mawwadah, Shohipatul. Efektifitas Pijat Oksitosin Dan Perawatan Payudara Terhadap Kelancaran Produksi ASI Pada Ibu Post Sectio Caesarea Di RSAD Wira Bhakti Mataram Thaun 2015. Fakultas Ilmu Kesehatan UNW Mataram; 2015

11. Desmawati. Penentu Kecepatan Pengeluaran Air Susu Ibu Setelah Sectio Cesarea. Jurnal Kesmas Nasional. Volume 7 ; 2013, 360-4. 